\title{
FACTORS AFFECTING TEMPERAMENT IN BUNAJI AND FRIESIAN-BUNAJI CROSSBRED CATTLE
}

\author{
B. Y. ABUBAKAR, O. O. ONI and A.E.O. MALAU-ADULA \\ National Animal Production Research Institute, \\ Ahmadu Bello University, P.M.B. 1096 \\ Shika-Zaria (Nigeria). \\ (Received 5 May, 1991, accepted 9 July, 1991)
}

\begin{abstract}
The influence of breed, sex, season, age, liveweight and body condition on temperament scores was investigated. All varibles, except age, had significant $(P<.05)$ effect on temperament. Progeny of crossbred dams had lower temperament than those of purebred bunaji dams. Female animals had higher temperament and so also were animals with better body condition. Temperament was lowest in the hot, dry season. Phenotypic correlations between measurements of temperament were positive and significant $(P<.05)$, with vigour of movement having the highest correlation with the overall temperament score. Liveweight was negatively correlated with temperament while there was a positive correlation between temperament and body condition. Regression equations for predicting overall temperament using vigour of movement are presented.
\end{abstract}

Key words: Bunaji, Friesian-Bunaji cattle; Temperament scores

\section{INTRODUCTION}

Temperament had been recognised as one of the limiting factors that could contribute to low animal productivity which is widely distributed across West Africa is reputed to be highly temperamental and as such least studied among the general considered to have more nervous temperaments than Bos taurus cattle (Hearnshaw et al.., 1979; Elder et al., 1980; Fordyce et al., 1982). Various methods have been used to measure temperament but most reports subjectively classify cattle into categories such as docile, restless, aggressive (Tulloh, 1961; Hearnshaw et al., 1979; Fordyce at al., 1985). Results with dairy cattle indicate that those with

Nigeria Journal of Animal Production 18 (1991) better temperament have better production (Drugociu et al., 1977; Gupta and Mishra, 1978) but Andersen et al. (1973) found that the temperament of bulls did not affect growth rates, food utilization or carcass quality.

The few estimates of heritability of temperament reported in the literature show low values for dairy cattle (Mishra et al., 1975; Persson, 1978; Wickham, 1979) and moderate values for beef cattle (Shrode and Hammack, 1971; Striklin et al., 1980; Fordyce et al., 1982. Other studies by Hearnshaw and Morris (1984) and Fordcy and Goddard (1984) have shown temperament to be moderately to highly repeatable. There is therefore a need to closely study factors, both environmental and animal, that affect temperament. This work was carried out with the objective of investigating the influence of breed, sex, season, age, liveweight and body condition on temperament scores in Bunaji and FriesianBunaji crossbred cattle.

\section{MATERIALS AND METHODS}

The investigation involved 204 animals made up of purebred Bunaji and Friesian- Bunaji crosses. The latter were progeny of either Bunaji or Friesian-Bunaji crossbred dams. Animals were part of the experimental herd of the National Animal Production Research Institute, Shika, locted in the Northern Guinea savanna zone of Nigeria. They are raised mainly on grass during the wet months of May - October while in the dry season, they receive hay or silage and concentrates. The animals were herded off grass at 08.00 , and temperament of each scored simultaneously by scorers for about 2 minutes in a weighbridge. Several behavious were scored. Vigour of movement (VOM) was scored on a six- 
point scale as follwos; 1 , no movement; 2 , slightly restless with minor movement; 3 , almost continuous but non-vigorous movement; 4 , quite vigorous movement; 5 , very disturbed and continuous vigorous movement; 6 , struggling violently and attempting to jump out.

The degree of audible respiration (DOR) was scored on four levels (Fordyce et al., 1985): 0, no audible respiration; 0.5 , heavy breathing; 1 , very heavy breathing; 1.5 , snorting. Other behavioral features scored were whether an animal knelt or laid down, bellowed or kicked (BKK). As each of these behaviours was infrequent, analysis was collective. Belowing and kicking were scored as 1 if they occured and 0 if they did not. A score of 2 was given for lying down. For each animal, scores for all behaviours were added to form the 'Temperament score' (TEM). Each of the scoies were replicated within a period of 24 hours. Body condition (CS) was scored following the technique outlined by Pullan (1978).

The effects of breed, sex, season, age, weight and body condition on the temperamen scores were examined by least squares procedures using SYSTAT (Wilkinson, 1988). Breed classification was either Bunaji, Friesian-Bunaji crosses with Bunaji dams or Friesian-Bunaji crosses with crossbred dams. Scores were taken over 3 seasons; wet (June), cool, dry (January) and hot, dry (April). Age was classified into animals less than 24 months and those older. The weight groups considered were $100 \mathrm{~kg}$ or less, between 101 and $200 \mathrm{~kg}$ and over $200 \mathrm{~kg}$. Body condition classification was either lean (Scores less than 3.5) or fat (scores of 3.5 or higher). Computed average scores of animals were used for the analyses. The model was as follows:

$$
\begin{aligned}
Y_{i j k l m n o}= & \underset{C}{U}+B_{i}+S_{x j}+S_{k}+A_{1}+W_{m}+ \\
& C S_{n}+E_{i j k l m n o}
\end{aligned}
$$

\section{Where;}

$\mathbf{Y}_{\mathrm{jik} / \mathrm{m} n \mathrm{o}}=$ the observation of the $\mathrm{o}^{\text {th }}$ animal with $\mathrm{n}^{\text {th }}$ body condition score in the $\mathrm{m}^{\text {th }}$ weight group of the $1^{\text {th }}$ age class within the $k^{\text {th }}$ season of the $j^{\text {th }}$ sex belonging to the $i^{\text {th }}$ breed;

$\mathrm{U}=$ the overall mean

$B_{i}=$ fixed effect of the $i^{\text {th }}$ breed $(i=1,3)$

$S_{x j}=$ fixed effect of the $j^{\text {th }} \operatorname{sex}(j=1,2)$
$S_{k}=$ fixed efect of the $k^{\text {th }}$ season $(k=1,3)$

$A_{1}=$ fixed eifect of the $1^{\text {th }}$ age group $(1=1,2)$

$W_{m}=$ fixee effect of the $m^{\text {th }}$ weight group

$$
(m=1,3)
$$

$\mathrm{CS}_{\mathbf{n}}=$ fixed effect of the $\mathrm{n}^{\text {th }}$ - condition score

$$
(\mathrm{n}=1,2)
$$

$E_{i j k \mid m n o}=$ random error associated with each record with expectation 0 and variance $0^{2}$

Phenotypic correlations were computed between variables. Linear regression within significantly different breed classes were fitted to predict overall temperament using vigour of movement only.

\section{RESULTS AND DISCUSSION}

The least square analysis of variance is shown in Table 1. and the lease squares means are given in Table 2. Breed differences were significant. Progeny with crossbred dams had significantly lower temperament $(<P .001)$ than those with Bunaji dams. Bellowing and kicking were also more exhibited in the former. This could be attributed to maternal breed differences since the anımals did not differ in body condition. Hearnshaw and Morris (1984) reported significant sire breed differences on temperament. Similar observations were made by Clay and Daly (1973) and Rudder et al. (1976). Sex effect was significant (P.001) with the females being more temperamental. However, there was virtually no detectable difference between the two sexes in degree of audible respiration. On the contrary, Hearnshaw and Morris (1984) found no significant differences could account for the observed disparity. Seasonal effects on temperament between steers and heifers. Brced differences could account for the observed disparity. Seasonal effects on temperament and body condition were significant $(P<, 001)$. In the wet and cool dry seasons, animals were more aggressive than in the hot dry season. The raeverse was expected since the environment seems to be harsher in the hot season duc to heat stress and less availability of fecd. On the otherhand, body condition was signilicantly lower in the hot than in the wet season. In addition, temperament was found to be significantly 
IABLE 1: LEAST SQUARES ANALYSIS OF VARIANCE FOR FACTORS AFFECTING TEMPERAMENT SCORES.

Mtan Squares

\begin{tabular}{llcclll} 
Source of Variation & DF & TEM & VOM & DOR & BKK & CS \\
\cline { 5 - 7 } & & & & & & \\
\hline Breed & 2 & $17.74^{\mathrm{b}}$ & $10.38^{\mathrm{b}}$ & $0.17^{\mathrm{a}}$ & $0.74^{\mathrm{B}}$ & 0.06 \\
Sex & 1 & $20.21^{\mathrm{b}}$ & $8.75^{\mathrm{b}}$ & 0.01 & $1.57^{\mathrm{b}}$ & 1.38 \\
Season & 2 & $9.76^{\mathrm{b}}$ & $2.35^{\mathrm{a}}$ & $0.16^{\mathrm{a}}$ & $1.85^{\mathrm{b}}$ & $10.89^{\mathrm{b}}$ \\
Age & 1 & 3.20 & $1.96^{\mathrm{a}}$ & 0.08 & 0.18 & 0.56 \\
Liveweight & 2 & $5.54^{\mathrm{a}}$ & $2.26^{\mathrm{a}}$ & 0.06 & $0.56^{\mathrm{a}}$ & $5.30^{\mathrm{b}}$ \\
Condition score & 1 & $7.10^{\mathrm{b}}$ & $4.38^{\mathrm{a}}$ & $0.53^{\mathrm{b}}$ & 0.10 & - \\
Residual & 361 & 1.14 & 0.63 & 0.05 & 0.13 & 0.65
\end{tabular}

${ }^{a} \mathrm{P}<0.05 \quad{ }^{\circ} \mathrm{P}<0.001$

TABLE 2: LEAST SQUARES MEANS FOR FACTORS AFFECTING TEMPERAMENT SCORES.

\begin{tabular}{|c|c|c|c|c|c|c|}
\hline Effect & Number & TEM & VOM & $\overline{\mathrm{DOR}}$ & $\overline{\text { BKK }}$ & $\mathrm{CS}$ \\
\hline Overall & 371 & 3.55 & 2.94 & 0.374 & 0.234 & 3. \\
\hline \multicolumn{7}{|l|}{ Breed } \\
\hline Bunaji & 89 & $3.73^{\mathrm{a}}$ & $3.04^{\mathrm{a}}$ & $0.358^{\mathrm{a}}$ & $0.295^{\mathrm{a}}$ & 3. \\
\hline Friesian cross ${ }^{\mathrm{a}}$ & 110 & $3.82^{\mathrm{a}}$ & $3.17^{\mathrm{a}}$ & $0.417^{f}$ & $0.267^{\mathrm{a}}$ & 3. \\
\hline Friesian cross ${ }^{b}$ & 172 & $3.12^{\mathrm{f}}$ & $2.61^{1}$ & $0.347^{\mathrm{a}}$ & $0.140^{a}$ & 3.1 \\
\hline
\end{tabular}

Sex

$\begin{array}{lllllll}\text { Males } & 97 & 3.23^{\mathrm{a}} & 2.73^{\mathrm{a}} & 0.372^{\mathrm{a}} & 0.144^{\mathrm{a}} & 3.09^{\mathrm{a}} \\ \text { Females } & 274 & 3.87^{\mathrm{f}} & 3.15^{\mathrm{f}} & 0.376^{\mathrm{a}} & 0.324^{\mathrm{f}} & 3.26^{\mathrm{a}}\end{array}$

Season

$\begin{array}{lllllll}\text { Wet } & 203 & 3.82^{\mathrm{a}} & 3.06^{\mathrm{a}} & 0.405^{\mathrm{a}} & 0.377^{\mathrm{a}} & 3.51^{\mathrm{a}} \\ \text { Cool, dry } & 96 & 3.64^{\mathrm{a}} & 3.02^{\mathrm{a}} & 0.392^{\mathrm{a}} & 0.208^{\mathrm{f}} & 3.09^{\mathrm{f}} \\ \text { Hot, dry } & 72 & 3.19^{\mathrm{f}} & 2.75^{\mathrm{f}} & 0.325^{\mathrm{f}} & 0.117^{\mathrm{f}} & 2.91^{\mathrm{f}}\end{array}$

Age,

$\begin{array}{lllllll}\leq 24 \mathrm{mo} & 18 \mathrm{~s} & 3.70^{\mathrm{a}} & 3.06^{\mathrm{a}} & 0.398^{\mathrm{a}} & 0.269^{\mathrm{a}} & 3.23^{\mathrm{a}} \\ >24 \mathrm{mo} & 188 & 3.40^{\mathrm{a}} & 2.83^{\mathrm{a}} & 0.350^{\mathrm{a}} & 0.199^{\mathrm{a}} & 3.11^{\mathrm{a}}\end{array}$

Liveweight

$\leq 100 \mathrm{~kg}$

$101-200 \mathrm{~kg}$

$200 \mathrm{~kg}$

$\begin{array}{llllll}63 & 3.89^{\mathrm{a}} & 3.09^{\mathrm{a}} & 0.412^{\mathrm{a}} & 0.345^{\mathrm{a}} & 2.88^{\mathrm{a}} \\ 156 & 3.61^{\mathrm{a}} & 3.05^{\mathrm{a}} & 0.375^{\mathrm{a}} & 0.172^{\mathrm{f}} & 3.08^{\mathrm{a}} \\ 1.52 & 3.15^{\mathrm{f}} & 2.69^{\mathrm{f}} & 0.335^{\mathrm{a}} & 0.185^{\mathrm{f}} & 3.56^{\mathrm{f}}\end{array}$

Body condition

$\begin{array}{lllllll}\text { Lean }^{\mathrm{c}} & 229 & 2.40^{\mathrm{a}} & 2.82^{\mathrm{a}} & 0.332^{\mathrm{a}} & 0.232^{\mathrm{a}} & - \\ \text { Fat }^{\mathrm{d}} & 142 & 317^{\mathrm{f}} & 3.06^{\mathrm{f}} & 0.416^{\mathrm{f}} & 0.236^{\mathrm{a}} & -\end{array}$

Dam is purebred Bunaji. ${ }^{b}$ Dam is Friesian-Bunaji cross ${ }^{c}$ Condition score 1 to $3.5 .{ }^{\circ}$ Condition score $>3.5$ Within each variable means followed by the same superscript are not significantly different. 
affected by condition of the animal with lean ones being more docile. It is therefore ot suprising that during the hot, dry season, animals were least aggressive. Albeit younger animals and higher temperament scores than older ones, the differences were not significant $(P>.05)$. Hearnshaw and Morris (1984) reported that cows had lower mean temperament scores than calves. They explained that cows had become accustomed to their management with age. In this study, animals in the higher weight group $(200 \mathrm{~kg})$ were significantly $(\mathrm{P}<.05)$ more docile. Those in the lower weight groups are predominantly younger animals so that there appears to be some confounding between weight and age. overall temperament score was significantly negatively correlated with liveweight; that is heavier animals had lower scores. This agrees with the findings or Tulloh (1961) and Fordyce et al. (1985). However, as stated earlier, there seems to be a confounding of age with weight and hence it would be more desirable to estimate correlations between growth rate and temperament. Condition score (CS) was significantly positively correlated with liveweight. For progeny of Bunaji dams, temperament scores were significantly positively correlated. with condition score. The relationship between these variables for progeny of crossbred dams was not significant except between DOR and CS (0.26). Since vigour of movement was highly correlated

TABLE 3: PHENOTYPIC CORRELATIONS BETWEEN TEMPERAMENT SCORES, LIVEWEIGHT AND BODY CONDITION.

\begin{tabular}{lllllll} 
Breed & Variables & VOM & DOR & BKK & LWT & CS \\
\hline $\mathbf{1}$ & TEM & 0.90 & 0.59 & 0.62 & -0.19 & 0.23 \\
$\mathbf{2}$ & & 0.90 & 0.49 & 0.66 & -0.36 & $0.14^{\mathrm{NS}}$ \\
$\mathbf{1}$ & VOM & & 0.46 & 0.38 & $-0.06^{\mathrm{NS}}$ & 0.23 \\
$\mathbf{2}$ & & 0.26 & 0.32 & -0.33 & $0.10^{\mathrm{NS}}$ \\
$\mathbf{1}$ & DOR & & & 0.26 & $-0.12^{\mathrm{NS}}$ & 0.17 \\
$\mathbf{2}$ & & & 0.22 & -0.17 & 0.26 \\
$\mathbf{1}$ & BKK & & & & $-0.07^{\mathrm{NS}}$ & 0.23 \\
$\mathbf{2}$ & & & & -0.20 & $0.05^{\mathrm{NS}}$ \\
$\mathbf{1}$ & LWT & & & & & 0.36 \\
$\mathbf{2}$ & & & & & 0.44
\end{tabular}

\footnotetext{
${ }^{\mathbf{a}}$ Breed 1 represents progeny of Bunaji dams.

Breed 2 represents progeny of Friesian-Bunaji crossbred dams

NS Not significant. All other correlations are significant $\mathrm{P}<.05$.
}

Phenotypic correlations between the scores, liveweight and condition score within breed classes are shown in Table 3. There were positive significant correlation between the various measures of temperament. Vigour of movement (VOM) had the highest correlation $(0.90)$ with the overall temperament score (TEM) followed by bellowing, kicking or kneeling (BKK) and then degree of audible respiration (DOR). Similar results were obtained by Fordyce et al., (1985) but their correlations were higher. The with the overall temperament score, regression equations were fitted within breed classes to predict TEM (Y) from VOM (X). The equations are:

(i) Progeny of Bunaji dams

$\mathrm{Y}=-0.06+1.237 \mathrm{X}\left(\mathrm{R}^{2}=0.81\right)$

(ii) Progeny of Crossbred dams

$\mathrm{Y}=-0.102+1.25 \mathrm{X}\left(\mathrm{R}^{2}=0.80\right)$ 
Polynomial equation did not appreciably improve the fits and are therefore not presented here.

If temperament is to be used as one of the criteria for selection in cattle improvement programmes within this environment, the results of this study indicate that it is necessary to adjust for the effects of breed, sex, season, liveweight and body condition. However, the study was based on experimental herds where the animals are used to routine handling. Therefore extension of such work to animals under field conditions is warranted.

\section{ACKNOWLEDGEMENT}

The authors acknowledge with gratitude the technical assistance of Mr. Tanimu Waziri and Mallam Shehu Haruna. The kind permission of the Director, NAPRI, to publish this work is also acknowledged.

\section{REFERENCES}

ANDERSEM, B. B., NIELSEN, A., LBORIUS SEN, T, KOUSGAARD, $K$. and BUCHTER, L., 1973. Progeny testing for beef production, VII. Beret. Forsoegslab. Stat ans Husdyrbrugsudvalg. No. 409, 51 pp.

CLAY, A. L. and DALY, J. J., 1973. The Africander in beef herds. Queensland agric. J., 99: 307-314.

DRUGOCIU, G., RUNCEANU, L., NICORICI, R., HRITCU, V. and PASCAL, S., 1977. Nervous typology of cows as a determining factor of sexual and productive behaviour. Anim. Breed. Abstr., 45: 1262 (Abstr.).

ELDER, J.K., WATERS, K.S., DUNWELL, G H., EMMERSON, F. R., KEARNAN, J.F., MORRIS, R. S. and KNOTT, C. G., 1984 A survey concerning cattle tick control in Queenlad. 2. Management aspects which indirectly affect tick control. Austr. Vet. J., S6: 205-211.
FORDYCE, G., DODDARD, M. E. and SEIFERT, G. W., 1982. The measurement of temperament in cattle and the effect of experience and genotype. Proseedings of the Australian Society of Animal Production. 14: 329-332.

FORDYCE, G. and GODDARD, M. E., 1984. Maternal influence on the temperament of Bos indicus cross cows. Proc. Aust. Soc. Anim. Prod., 15: 345-348.

FORDYCE, G., GODDARD, M. E., TYLER, R., WILLIAMS, G. and TOLEMAN, M. A., 1985. Temperament and bruising of Bos indicus cross cattle. Aust. J. of Expt. Agric., 25: 283-288.

GUPTA, S. C. and MISHRA, R. R., 1978. Temperament and its effect on miling ability of Karan Swiss cows. Proc. 20th Int. Dainy Congr., Paris, Vol. E. Pp 130.

HEARNSHAW, H., BARLOW, R. and WANT, G., 1979. Development of a 'temperament' or 'handling difficulty' score for cattle. Proc. Aust. Assoc. of Animal Breed. and Genetics., 1: 164-166.

HEARNSHAW, H. and MORRIS, C. A., 1984. Genetic and environmental effects on a temperament score in beef cattle. Aust. $J$. of Agric. Res., 35 : 723-733.

MISHRA, R. R., CHUHAN, R. S. and GUPTA, S. C. 1975. Studies of dairy temperament of karan Swiss cows. Indian J. of Diary Sci.. 28: 85-88.

PERSSON, E., 1978. Analysis of test milk data. Husdjur, 11: 16-20.

PALLAN, N. B., 1978. Condition scoring of White Fulani cattle. Trop. Anim. Health and Prod, 10: 119-120.

RUDDER, T. H., SEIFERT, G. W. and VER- 
COE, J. E.; 1976. Belmont Red - a promising breed for the tropics. Queensl. Agric. J., 102: 17-21.

SHRODE, R. R. and HAMMACK, S. P., 1971. Chute behaviour of yearling beef cattle. $J$. Anim. Sci., 33: 193 (Abstr.).

STRICKLIN, W. R., HEINSLER, C. E. and WILSON, L. L., 1980 . Heritability of temperament in beef cattle. J. of Anim. Sci., 51: 109 (Abstr.).
TULLOH, N. H., 1961. Behaviour of cattle in yerds: II. A study of temperament. Anim. Behav., 9: 25-30.

WICKHAM, B. W., 19,79. Genetic parameters and economic values of traits other than production for dairy cattle. Proc. New Zealand Soc. Anim. Prod., 39: 180-193.

WILKINSON, L., 1988. SYSTAT. The system for statistics. Evanston, IL: SYSTAT, Inc. 